\title{
TRANSPLANTE HEPÁTICO: PROBLEMAS DE ENFERMAGEM EM PACIENTES NO PÓS-OPERATÓRIO
}

\author{
Liver transplantation: nursing problems in patients during the postoperative phase
}

Telma Christina do Campo Silva, Rachel de Carvalho

\begin{abstract}
RESUMO
Estetrabal ho teve por finalidade levantar os problemas de enfermagem na clínica cirúrgica, oferecendo elementos paraaSistematização daA ssistência de Enfermagem. Objetivos: identificar o perfil epidemiológico e os problemas de enfermagem no período pós-operatório imediato de pacientes submetidos a transplante hepático. M étodos: utilizou-se análise retrospectiva por meio do acesso ao prontuário digitalizado de pacientes submetidos a transplante hepático no período de um ano, durante o qual 35 pacientes foram submetidos ao procedimento. Resultado: foram identificados 312 problemas de enfermagem. Conclusão: Os sistemas com maior número de problemas associados foram: gastrointestinal, respiratório, cutâneomucoso e neurológico, sendo os problemas de enfermagem de maior incidência: abdome globoso e doloroso à pal pação, oligúria, incisão cirúrgica serossanguinolenta, icterícia e prurido, períodos de confusão, murmúrios vesiculares diminuídos e edema.
\end{abstract}

Descritores: Transplante de Fígado, Hepatopatias, Enfermagem, A ssistência ao Paciente, Período Pós-O peratório.

Instituição:

Unidade de Transplante de Órgãos do Hospital Israelita Albert Einstein (HIAE) e apresentado como Trabalho de Conclusão de Curso (TCC) - São Paulo - SP

Correspondência:

Telma Christina do Campo Silva

Avenida Grande São Paulo ㄲo 373

CEP: 04843-040 - São Paulo - SP

Tel: 5511 5928-0194 / 5511 9700-0374

E-mail: telma.chris@bol.com.br

Recebido em: 10/10/2005

Aceito em: 19/12/2005

\section{INTRODUÇÃO}

0 transplante defígado éuma modalidadeterapêutica que possibilitaa reversão do quadro terminal de um paciente com doença hepáticae, em muitas situações, constitui-se no único tratamento para pacientes com patologias em que há dano irreversível de algum órgão ou tecido.

0 primei ro transplante hepático em humanos foi realizado em 1963, e o primeiro com sucesso em 1967, ambos nos Estados Unidos. ${ }^{1,2}$ 0 surgimento da ciclosporina, em 1977, marcou definitivamente a história dos transplantes e possibil itou o controle das rejeições e das infecções oportunistas. ${ }^{2}$ No B rasil, o primeiro transplante hepático com sucesso foi realizado pelo Professor Silvano Raia, em setembro de 1985, na Faculdade de M edicina da U niversidade de São Paulo.

Quanto às modalidades de transplante hepático, devem-se considerar o doador cadáver, 0 doador vivo, 0 dominó e o split. $^{3} \mathrm{Em}$ relação à topografia em que o enxerto será implantado, classificamse os transplantes em ortotópico (ocupa o sítio anatômico do órgão) e heterotópico (outras localizações). ${ }^{4}$

0 transplante de fígado é compreendido como um processo que pode ser dividido em quatro períodos consecutivos: a inclusão do pacientena lista de espera, o preparo e a espera para a real ização do procedimento, o transplante propriamente dito e o período pós-operatório. ${ }^{5}$

A indicação do transplante é feita quando o paciente apresenta um prognóstico de sobrevida de aproximadamente 12 meses, devido à doença hepática e, segundo dados da Secretaria Estadual de Saúde de São Paulo, o tempo médio na lista de espera é de aproximadamente 357 dias. $^{6}$

De acordo com a A ssociação B rasileira de Transplantes de Órgãos (A BTO), cerca de 7.500 transplantes são realizados anual mente em, aproximadamente, 200 centros internacionais, sendo que, no 
Brasil, há 25 centros catalogados que realizam o transplante de fígado. ${ }^{7}$ A sobrevida relatada na literatura varia de 80 a $90 \%$ nos dois primeiros anos e de 55 a $70 \%$ em nove anos. ${ }^{8}$

A indicação do transplante de fígado está reservada a portadores de insuficiência hepática crônica terminal que têm expectativa de vida inferior a 20\% ao final de 12 meses, se não forem transplantados, e àquel es cuja progressão da doença hepática resulta em mortalidade que exceda aquela decorrente do próprio transplante. B asicamente, a indicação do transplante hepático tem por objetivo prolongar a vida do paciente, proporcionando satisfatória qualidade de vida e recuperação do trabalho. ${ }^{9}$

A qualidade de vida após o transplante é um padrão para aval iação do procedimento cirúrgico. Portanto, trabal har com esse tipo de procedimento requer uma análise cuidadosa daqueles doentes. 8 N os aspectos psicológicos, os pacientes do programa de transplante apresentam grande ansiedade e carência afetiva. ${ }^{5}$

O sucesso do pós-operatório baseia-seno manuseio do paciente, tanto na sala de cirurgia quanto nos primeiros dias após o ato cirúrgico. N esta fase, rápidas modificações ocorrem na função hepática, que dependem da integração de um grupo de especialistas. ${ }^{5}$

A assistência ao paciente transplantado é al tamente especializada, requerendo a atuação do enfermei ro nas diversas fases do processo, e exigindo pessoal com capacitação específica. A fragmentação da assistência de enfermagem pode fazer com que o enfermeiro perca a noção do todo.

O s enfermei ros que prestam assistência ao paciente durante o período de internação desconhecem a assistência pré e pós-transplante prestada no ambulatório. A falta de continuidade do trabalho e de integração entre os diferentes membros da equipe não assegura aos pacientes o recebimento das orientações necessárias. ${ }^{5}$

O s objetivos deste trabal ho foram: identificar o perfil epidemiológico e os problemas de enfermagem no período pós-operatório imediato de pacientes submetidos a transplante hepático.

\section{MÉTODO}

A pesquisa foi realizada no Hospital Israelita A lbert Einstein (HIAE ), onde a maioria dos transplantes é custeada pelo Sistema Ú nico de Saúde (SUS), com média de 7,5 transplantes hepáticos mensais, sendo $60 \%$ do tipo ortotópico com doador cadáver. ${ }^{10}$

A amostra deste estudo foi composta pela totalidade dos pacientes submetidos ao transplante hepático ortotópico, no período de janeiro a dezembro de 2003.

0 instrumento para a realização da coleta de dados foi elaborado pelas autoras e constou de duas partes. A primeira parte identifica o perfil epidemiológico dos pacientes que foram submetidos ao transplante hepático, com informações referentes a sexo, cor, idade, procedência, patologias associadas, indicação do transplante, tempo de espera na fila e modalidade do transplante. A segunda parte contém o levantamento de problemas de enfermagem, seguindo o sentido céfalo-caudal e utilizando o modelo do Processo de Enfermagem proposto por Wanda de A guiar Horta.

A coleta de dados foi realizada após o projeto ter sido aprovado pela Comissão Científica da Faculdade deE nfermagem do H ospital Israelita A lbert Einstein (FEHIAE) e pelo Comitê de Ética em Pesquisa do Hospital Israelita A lbert Einstein (HIAE), bem como depois da autorização da coordenadora do Serviço de Prontuário do Paciente
(SPP). 0 acesso ao prontuário retroativo digital izado dos pacientes submetidos a transplante hepático foi realizado no segundo semestre de 2004, utilizando-se os registros de enfermagem das primeiras 24 horas de permanência do cliente na unidade de internação ( período pós-operatório imediato).

Os dados obtidos foram analisados e agrupados por meio da medida estatística descritiva de comparação de freqüência, agrupando-se o perfil epidemiológico e os problemas de enfermagem.

\section{RESULTADOS}

No período determinado para o estudo, 35 pacientes foram submetidos ao transplante hepático.

D estes, $62,86 \%$ (22 pacientes) eram do sexo masculino. Em relação à cor, $68,60 \%$ (24 pacientes) eram da cor branca, seguidas pelas cores negra e parda com 14,30\% (cinco pacientes) cada uma, e amarela com $2,80 \%$ (um paciente). A média de idade foi de 53 anos, porém $34,30 \%$ (12 pacientes) estavam no intervalo entre 60 e 70 anos.

Verificamos que $22,86 \%$ (oito pacientes) desta amostra eram provenientes de outros estados brasileiros e 77,14\% (27 pacientes) do estado de São Paulo.

Devido à gravidade clínica resultante da hepatopatia, muitos pacientes apresentavam patologias associadas ao transplante, sendo que neste estudo, a maior incidência foi de Insuficiência Renal A guda (IR A) com 28,57\% (dez pacientes), seguida por Diabetes M ellitus e Encefalopatia, cada uma com 25,71\% (nove pacientes). Em relação à indicação do transplante, 51,45\% (18 pacientes) realizaram o transplante devido à cirrose causada pelo vírus da hepatite C (VHC), seguida pela cirrose associada ao hepatocarcinoma $25,73 \%$ (nove pacientes).

A média do tempo de espera pelo transplante foi de 23,37 meses. Em relação à modalidade do transplante, 60\% (21 pacientes) receberam 0 enxerto de doador cadáver, seguido pelo de doador vivo, com $25,70 \%$ (nove pacientes), o dominó com 8,60\% (três pacientes) e o split representou $5,70 \%$ (dois pacientes) da amostra. A taxa de retransplante foi de $8,60 \%$ (três pacientes).

Da totalidade dos casos, $20 \%$ (sete pacientes) evoluíram para óbito, 8,60\% (três pacientes) ocorreram devido a choque séptico, seguido por assistolia com 5,80\% (dois pacientes), choque cardiogênico e recidiva de hepatocarcinoma, cada um com $2,80 \%$ (um paciente).

Foram identificados 312 problemas de enfermagem divididos em oito categorias, seguindo o modelo empregado para a técnica do exame físico.

A nalisando a ocorrência de problemas de enfermagem por sistemas orgânicos, verifica-se que as maiores incidências recaíram sobre o aparel ho gastrointestinal $(21,48 \%)$ e aparelho respiratório $(19,23 \%)$, seguidos dos sistemas cutâneo-mucoso $(14,42 \%)$, neurológico (12,82\%), gênito-urinário (9,94\%) músculo-esquelético e cardiovascular (7,69\%), e endócrino (6,73\%).

\section{DISCUSSÃO}

D os 35 pacientes submetidos ao transplante hepático, 62,86\% (22 pacientes) eram do sexo masculino, incidência confirmada em outro estudo, ${ }^{11}$ onde $57,14 \%$ dos pacientes pertenciam a este sexo. Em relação à cor, 68,60\% (24 pacientes) eram da cor branca, seguidas pelas cores negra e parda, com $14,30 \%$ (cinco pacientes) cada uma. 
A média de idade foi de 53 anos, com predominância de 34,30\% , (12 pacientes) no intervalo entre 60 e 70 anos, demonstrando o aumento da expectativa devida. Em um estudo sobre diagnósticos deenfermagem, ${ }^{10}$ a média de idade dos pacientes transplantados foi de 44 anos.

Existem, atual mente, 19 centros que realizam transplantes de fígado no B rasil, dos quais dez localizam-se na cidade de São Paulo. ${ }^{12} \mathrm{~A}$ migração de pacientes para serem incluídos em listas de grandes centros transplantadores é comum. A ssim, verificamos que $22,86 \%$ (oito pacientes) desta amostra eram provenientes de outros estados brasileiros e 77,14\% (27 pacientes) eram do estado de São Paulo.

Por conta da gravidade clínica resultante da hepatopatia e da carência de doadores, muitos pacientes apresentavam patologias associadas ao transplante, ${ }^{3}$ sendo que neste estudo a maior incidência foi de Insuficiência Renal A guda (IRA), com 28,57\% (dez pacientes), seguida por Diabetes M ell itus e Encefalopatia cada uma com $25,71 \%$ (nove pacientes).

Os dados obtidos confirmam a grande incidência, 51,45\% (18 pacientes) de transplantes hepáticos realizados por cirrose causada pelo vírus da hepatite $\mathrm{C}(\mathrm{V} \mathrm{HC})$. A cirrose de etiologia viral constitui uma das principais indicações ao transplante hepático, ${ }^{12}$ seguida pela cirrose associada ao hepatocarcinoma $25,73 \%$ (nove pacientes), que, em portadores de cirrose de etiologia viral, tem baixa incidência de recidiva. ${ }^{3}$ Em contrapartida, no trabalho sobre diagnósticos de enfermagem, ${ }^{10}$ a segunda maior indicação foi cirrose causada pelo vírus da hepatite B (V HB ), (22\%) e, neste estudo, essa patologia foi responsável por apenas uma indicação cirúrgica, ou seja 2,85\% dos casos conforme verifica-se na Figura 1.

Figura 1. Pacientes submetidos ao transplante hepático, segundo a indicação cirúrgica

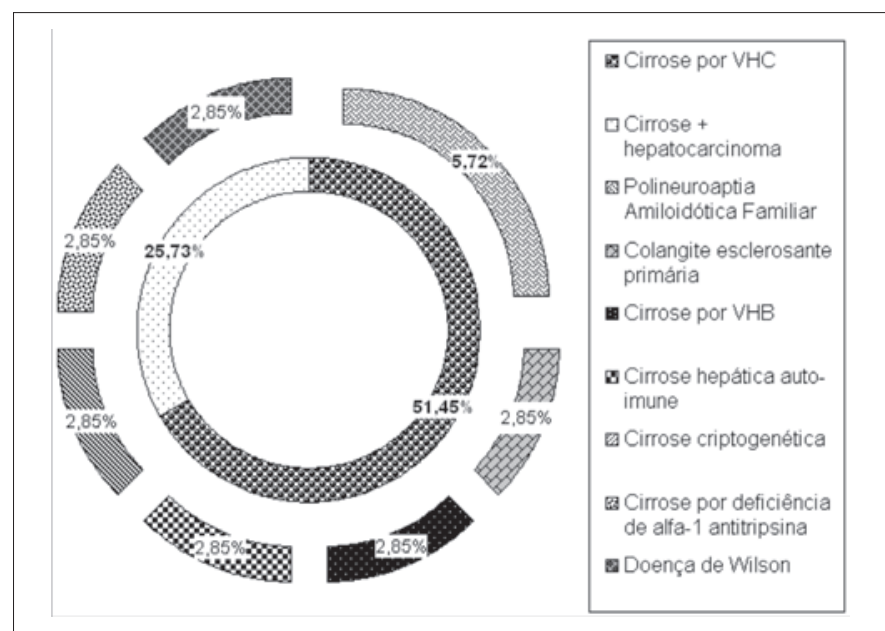

VHB: Vírus da hepatite $B$

VHC: Vírus da hepatite $C$

A média do tempo de espera pelo transplante foi de 23,37 meses. As equipes transplantadoras vêm enfrentando como desafio a escassez de doadores de órgãos, visto que a demanda não é suficiente para atender a todos os pacientes que necessitam dessa terapêutica, e muitos morrem à espera do transplante..$^{13}$

E $m$ relação à modalidade do transplante, $60,0 \%$ (21 pacientes) receberam 0 enxerto de doador cadáver, comprovando que estes são a maior fonte de órgãos para os transplantes33; o número de nãodoadores ainda é muito grande, principal mente se considerarmos que a mídia vem demonstrando a necessidade de aumentar esse número e vem retratando os problemas vividos pelas pessoas que necessitam de transplante de órgãos. Com o intuito de possibilitar o transplante em estágios mais precoces da insuficiência hepática, foi iniciada a captação de enxertos hepáticos de doadores vivos relacionados, ${ }^{14}$ sendo que neste estudo esta modalidade corresponde a $25,70 \%$ (nove pacientes). 0 dominó foi responsável pelo transplante em $8,60 \%$ (três pacientes), e o split, também conhecido como transplante compartilhado, representou 5,70\% (dois pacientes) da total idade dos transplantes neste estudo.

A taxa de retransplante foi de $8,6 \%$ (três pacientes), sendo que todos os casos foram devido à trombose da artéria hepática. A s complicações vasculares são uma das mais sérias no pósoperatório, por conta da diferença vascular entre doador e receptor e da dificuldade de anastomose. Nenhum caso desta amostra foi submetido a re-re-transplante.

Da totalidade dos casos, 20\% (sete pacientes) evoluíram para óbito, sendo que apenas um caso estava associado à trombose da artéria hepática e 8,60\% (três pacientes) ocorreram devido a choque séptico. Em um estudo sobre óbito tardio em transplantados de fígado, ${ }^{15}$ a maioria dos óbitos ocorreu nos três primei ros meses após o transplante e foram devido à infecções, complicações técnicas e não funcionamento primário do enxerto. Neste estudo, um paciente apresentou óbito devido à recidiva de hepatocarcinoma. Os pacientes submetidos a transplante têm incidência aumentada de tumores, sendo que essas neoplasias variam conforme o tipo de órgão transplantado, esquema de imunossupressão e tempo de acompanhamento.

0 enfermeiro deve sempre investir esforços na identificação e prevenção de complicações, bem como intervir para proporcionar recuperação integral e melhor qualidade de vida ao paciente que se submete a transplante hepático. ${ }^{16}$

A pós a caracterização da amostra e da leitura dos registros contidos no prontuário do paciente, os problemas de enfermagem foram identificados, totalizando 312 problemas divididos em oito categorias, seguindo o modelo empregado para a técnica do exame físico de acordo com os sistemas orgânicos e no sentido céfalo-caudal. (Tabela 1).

A nal isando a ocorrência de problemas de enfermagem por sistemas orgânicos, verifica-se (Tabela 1) que as maiores incidências recaíram sobre 0 aparel ho gastrointestinal $(21,48 \%)$ e aparelho respiratório (19,23\%), seguidos dos sistemas cutâneo-mucoso $(14,42 \%)$ e neurológico (12,82\%). Q uanto às ocorrências individuais, discuti remos apenas os problemas de enfermagem identificados em sete ou mais pacientes.

Sistema Neurológico: períodos de confusão presentes em 18 pacientes, e agitação psicomotora com incidência em dez pacientes. M uitos pacientes apresentam graus variáveis de encefal opatia hepática no período pós-operatório, devido à concentração aumentada de amônia e de outros metaból itos tóxicos no sangue, provocando lesão e disfunção cerebral. 0 paciente passa por períodos de confusão, alterações de humor e do padrão de sono, ou seja, tende a dormir de dia e a ficar agitado e ter insônia à noite. ${ }^{14}$ 
Figura 1. Pacientes submetidos ao transplante hepático, segundo a indicação cirúrgica

\begin{tabular}{lrr}
\hline Sistema & $\mathbf{n} \mathbf{0}$ & \% \\
\hline Neurológico & 40 & 12,82 \\
Endócrino & 21 & 6,73 \\
Respiratório & 60 & 19,23 \\
Cardiovascular & 24 & 7,69 \\
Gastrointestinal & 67 & 21,48 \\
Gênito-urinário & 31 & 9,94 \\
Cutâneo-mucoso & 45 & 14,42 \\
Músculo-esquelético & 24 & $\mathbf{7 , 6 9}$ \\
\hline Total & $\mathbf{3 1 2}$ & $\mathbf{1 0 0 , 0 0}$ \\
\hline
\end{tabular}

Sistema E ndócrino: os picos de hiperglicemia estiveram presentes em 20 pacientes, estando relacionados aos efeitos intrínsecos dos imunossupressores, aumento da resistência a esse hormônio e, possivel mente, efeitos tóxicos diretos sobre as células $\beta$ das il hotas pancreáticas. A hiperglicemia ocorre no período pós-operatório, podendo comportar-se como simples intolerância transitória à glicose que necessita do uso temporário da insulina. A minoria dos pacientes requer seu uso permanente. ${ }^{17}$

Sistema Respiratório: murmúrios vesiculares diminuídos presentes em 18 pacientes; tosse seca e taquipnéia com freqüência de 16 pacientes cada uma. As complicações do sistema respiratório são comuns após o transplante em razão da intoxicação hídrica em pacientes com insuficiência hepática termi nal, associada a certo grau de hiper-hidratação decorrente da politransfusão e dos freqüentes desequilíbrios hidroeletrolíticos intra-operatórios. 0 comprometimento da excursão diafragmática é bastante freqüente e relacionado ao acúmulo de ascite, extensa manipulação cirúrgica do diafragma, lesão do nervo frênico durante o clampeamento da veia cava inferior supra-hepática. ${ }^{14}$ Os murmúrios vesiculares diminuídos, a tosse seca e a taquipnéia, decorrentes da dor e da distensão abdominal, devem ser tratados de forma intensiva com fisioterapia respiratória. Na vigência de imunossupressão e as atelectasias podem propiciar o aparecimento de pneumonias graves, de difícil tratamento. ${ }^{3}$

Sistema Cardiovascular: hipertensão arterial sistêmica (HAS), com incidência em 14 pacientes. A HAS é decorrente da intensa vasoconstrição sistêmica que ocorre no pós-operatório do transplante hepático, somada à hiper-hidratação do pós-operatório precoce e à retenção de sódio eágua decorrentes da admi nistração de corticóides e imunossupressores. ${ }^{3}$ Como a hipertensão pode ser a manifestação da toxicidade da ciclosporina, a adequação de seus níveis séricos é fundamental para o controle da pressão arterial. A circulação hiperdinâmica, a hipervolemia, as alterações no metabolismo de agentes vasoativos endógenos e os efeitos secundários da administração de drogas podem levar à taquicardia ${ }_{1}^{14}$ sendo que neste estudo ela ocorreu em sete pacientes.

Sistema G astrointestinal: 0 abdome globoso e doloroso à pal pação presente em 25 pacientes é bastante freqüente, pois além dos pacientes serem submetidos a um grande trauma cirúrgico, durante aquele período eles têm a mobilidade física deficiente e a motilidade intesti nal diminuída. ${ }^{3}$ Em razão da extensão da ferida, do prolongado tempo operatório, dos distúrbios de coagulação intra-operatórios, da necessidade de abertura do tubo digestivo para a confecção da drenagem biliar e da imunossupressão associada, o transplante hepático é um procedimento potencial mente contaminado eassociado a freqüentes complicações incisionais sendo que, neste estudo, a presença de secreção serossanguinolenta na incisão tevef reqüência de 21 pacientes.$^{14} \mathrm{~N}$ o pós-operatório do transplante apresentam-se outras condições que propiciam a desnutrição, como náuseas evômitos (nove pacientes) que redundam em diminuição da ingestão de alimentos, 0 que proporciona ao paciente uma chance maior de adquirir infecções pós-operatórias em decorrência da desnutrição. ${ }^{17}$

Sistema G ênito-urinário: oligúria, presente em 23 pacientes. A lgum grau de disfunção renal sempre está presente no período pós-operatório; em geral, a oligúria após o transplante se instala pela perda de sangue no intra-operatório..$^{18} \mathrm{E}$ ssa ol igúria é quase sempre autolimitada, não exigindo terapia específica, porém, deve-se garantir adequado volume intravascular e ótimo débito cardíaco. ${ }^{14}$

Sistema C utâneo-mucoso: a icterícia e o prurido estiveram presentes em 19 pacientes. Estas complicações são comuns no pósoperatório, pois 0 enxerto ainda não restabeleceu suas funções. A icterícia ocorre quando a concentração de bilirrubina no sangue está elevada de maneira anormal. Os pacientes com disfunção hepática desenvolvem prurido devido à retenção de sais biliares. ${ }^{14}$ A pós o transplante, quando o fígado recobra sua função, os sangramentos que ocorriam começam a diminuir, porém, o paciente transplantado ainda apresenta alterações na cascata de coagulação sangüínea. ${ }^{18}$ Neste estudo, o hematoma em membros superiores foi ocorrência em 15 pacientes. A anasarca teve freqüência em sete pacientes, ocorrendo como resultado da administração excessiva de líquidos, principalmente hemocomponentes, e também associado ao comprometimento do mecanismo regulador. ${ }^{3}$

Sistema M úsculo-esquelético: 0 edema em membros superiores e inferiores esteve presente em 18 pacientes. Muitos pacientes apresentam acúmulo de líquidos, sobretudo sob a forma de edema. Esse líquido começa a ser mobilizado cerca de 48 horas após 0 término do transplante. Entretanto, em razão da hipoal buminemia, da extensa área da dissecção cirúrgica, da administração de volume hipertônico durante a anestesia, além dos efeitos determinados pelo uso de imunossupressores e por altas doses de corticóides, o processo de redimensionamento do compartimento intersticial pode demorar algumas semanas. ${ }^{14}$

A caracterização de uma classe de pacientes submetidos a esse procedimento tão complexo nos possibilitou visualizar os principais problemas de enfermagem que ocorrem nas primeiras 24 horas de permanência do cliente na unidade de internação, no período pós-operatório imediato. Diante da grande complexidade desses pacientes, faz-se necessária a construção de diretrizes para a Sistematização da A ssistência de Enfermagem, já que esses clientes estão permeados por complicações e internações recorrentes. 0 levantamento dos problemas de enfermagem no pós-operatório 
oferece padronização de condutas dos profissionais e a construção de parâmetros de qualidade para assistência acarreta redução da possibilidade de complicações pós-operatórias.

\section{CONCLUSÃO}

A análise dos prontuários dos 35 pacientes submetidos ao transplante hepático em 2003 permitiu-nos concluir que os pacientes eram, em sua maioria, do sexo masculino, de cor branca, pertencentes à faixa etária entre 60 e 70 anos, procedentes do estado de São Paulo, com IR A como patologia associada, indicação cirúrgica devido à cirrose por V HC, tempo médio de espera na fila do transplante de $e^{23,37}$ meses e 21 transplantes realizados com doador cadáver.

A análise dos dados obtidos pela coleta de informações referentes às anotações, evoluções e prescrições de enfermagem permitiu identificar 312 problemas de enfermagem, seguindo o sentido céfalocaudal. Os sistemas com maior número de problemas associados foram: gastrointestinal, respiratório, cutâneo-mucoso eneurológico. Os problemas demaior incidênciaforam: abdomegloboso edoloroso à pal pação, oligúria, incisão cirúrgica serossanguinolenta, icterícia e prurido, períodos de confusão, murmúrios vesiculares diminuídos e edema.

\section{ABSTRACT}

The aim of this study is to raise the nursing problems in the surgical clinic, providing elements for the Systematization of the Nursing Assistance. Purposes: to identify the epidemiological profile and nursing problems in the immediate postoperative phase of patients submitted to liver transplantation. M ethods: a retrospective analysis was used by assessing the medical records of patients submitted to liver transplantation along an one-year period, in which 35 patients were submitted to the procedure. Results: a total of 312 nursing problems were identified. Conclusion: those systems with the higher amount of associated problems were: gastrointestinal, respiratory, cutaneousmucous, and neurological. The nursing problems that presented higher frequency were: soft and swollen abdomen on palpation, oliguria, serosanguinous surgical incision, jaundice and itching, periods of confusion, reduced vesicular murmurs and edema.

Keywords: Liver Transplantation, Liver Diseases, Nursing, Patient Care, Postoperative Period.

\section{REFERÊNCIAS}

1. Nehme CS. Histórico do transplante de fígado [on line]2003; São Paulo [citado 2003 fev 01]. Disponível em URL: http://www.transpatica.org.br/frame5.htm.

2. Assis FN. Histórico do transplante de fígado [on line]2003; São Paulo [citado 2003 fev 03]. Disponível em URL: http://www.adote.org.br/projetos/doe/html.

3. Chapchap P, Carone E. Transplante hepático. In: Neumann J, Filho MA, Garcia VD. Transplante de órgãos e tecidos. $1^{a}$ ed. São Paulo: Sarvier; 1997. p.290-2.

4. Alfieri FJ, Mies S. Transplante de órgãos: bases fisiopatológicas e técnicas. In: Goffi FS, Gonçalves JJ, Benassi EL, Buenno ELR, Mies S, Alfieri FJ. Técnicas cirúrgicas: bases anatômicas, fisiopatológicas e técnicas da cirurgia. 4a ed. São Paulo: Atheneu; 2001. p.158-67.

5. Massarolo MCKB, Kurcgant P. O vivencial dos enfermeiros no programa de transplante de fígado de um hospital público. Rev Lat Am Enfermagem, Ribeirão Preto. 2000;8(4):66-72.

6. Neto BHF, Afonso RC, Saad WA. Situação do transplante hepático no Brasil: diagnóstico e tratamento, São Paulo. 1999;4(3):7-10.

7. Associação Brasileira de Transplante de Órgãos (ABTO). Registro Basileiro de Tansplantes [on line]2003. São Paulo [citado 2004 out 28]. Disponível em URL: http://www.abto.org.br/população/profissionais/gráficos.htm.

8. Udo EY, Boin IFSF, Biella S, Leonardi LS. Perfil sócio-econômico dos receptores de fígado: correlação com aderência ao programa de transplante hepático. J Bras Transpl, São Paulo. 2001;4(2):35-9.

9. Silva OCJ, Sankarankutty AK, Oliveria GR, Pacheco E, Ramalho FS, Sasso KD, et al Transplante de fígado: indicação e sobrevida. Acta Cir Bras, Rib. Preto. 2002;17(3):83-7.
10. Canero TR, Carvalho R, Galdeano LE. Nursing diagnoses for the immediate postoperative period of patients submitted to liver transplantation. Rev. Einstein, São Paulo. 2004;2(2):100-4.

11. Machado MM, Rosa ACF, Barros N, Cerri LMO, Cerri GG. Coleção líquida adjacente ao ligamento falciforme em pacientes no pós-operatório imediato de transplante de fígado: achado ultra-sonográfico normal ou anormal? Estudo prospectivo. Radiol Bras, São Paulo. 2003;36(2):77-9.

12. Mies S. Transplante de fígado. Rev. Assoc. Med. Bras, São Paulo. 1998;44:(2):127-34.

13. Moraes MW. Caracterização dos determinantes sócio-culturais que influenciam os adolescentes na atitude de ser "doador de órgãos”. [dissertação]. São Paulo: Escola de Enfermagem da Universidade de São Paulo (EEUSP); 2001.

14. Marujo WC, Barros MFA, Cury RA, Sette HJ. Transplante de fígado. In: Knobel E, Marujo WC, Barros MFA, Cury RA, Sette HJ, Ramalho AJ. Condutas no paciente grave. 2a ed. São Paulo: Atheneu; 1998.p.1135-47.

15. Coelho JCU, Parolin MB, Matias JEF, et al. Causa de óbito tardio em transplantados de fígado. Rev Assoc Med Bras, São Paulo. 2003;49(2):177-80.

16. Sasso KD, Azevedo MAJ. Assistência de enfermagem no transplante de fígado: a importância do enfermeiro nessa modalidade terapêutica. Nursing, São Paulo. 2003;60(6):16-20.

17. Parolin MB, Zaina FE, Lopes RW. Terapia nutricional no transplante hepático. Arq Gastroenterol, São Paulo. 2002;39(2):114-21.

18. Rocha ABL, Kina C, Lourenzen R, Silva SC. Assistência de enfermagem a pacientes submetidos ao transplante hepático: cuidados intensivos no pós-operatório. Nursing, São Paulo. 2000;32:18-22. 